\title{
The Imperative of the Ethics of Complementarity in the Quest for Africa' Development
}

\author{
Solomon Akinyemi Laleye ${ }^{1}$ \\ ${ }^{1}$ Department of Philosophy, Adekunle Ajasin University, Akungba-Akoko, Ondo State, Nigeria \\ Correspondence: Solomon Akinyemi Laleye, Department of Philosophy, Adekunle Ajasin University, \\ Akungba-Akoko, Ondo State, Nigeria. Tel: 234-80-3490-1172. E-mail: laleyesolomon@gmail.com
}

Received: April 6, 2018

Accepted: May 2, 2018 Online Published: May 30, 2018

doi:10.5539/jsd.v11n3p251

URL: https://doi.org/10.5539/jsd.v11n3p251

\begin{abstract}
The Externalists and Internalists interrogated the crisis of development in Africa and have suggested solutions. In response to the challenge, successive governments have adopted theories, initiated policies and strategies to remedy the situation. In spite of these efforts, the attainment of a commendable stage of development has eluded majority of African nations, this is largely because the conception of development is erroneously predicated on the monistic neglecting the dualistic aspects of development. This paper, does not only correct this misconception it also philosophically explore how Africa can overcome contemporary and future sustainable development challenges, by articulating sustainable development paradigm appropriate for the continent. The paper argued for the necessity of a complement involving the quantitative and qualitative aspects of the dualistic conception rather than a straight jacketed approach that focuses more on the quantitative aspect in the quest for development. The paper employs the analytic and prescriptive approaches of philosophical inquiry.
\end{abstract}

Keywords: social development, ethics of complementarity, quantitative, qualitative

\section{Introduction}

From the inception of society, humans have not rested on their oars to improve on the conditions that define their existence. Individuals and societies strive to vacate conditions considered as unsatisfactory to more prosperous and advanced ones. The search for more desirable conditions that can enhance human wellbeing are visible in most spheres of human existence; the economic, political, religious, social, technological, educational, cultural and moral. Many nations, particularly the stigmatized Third world countries are deficient in some of these spheres notwithstanding, it is a rarity for any society to be backward in all of these spheres. In this regard, it is logically appropriate to conclude that human society is not static, it is dynamic. The dynamism of human society, therefore, is partly a function of the quest for positive transformation in all or some of these areas.

Positive transformation as a universal value cherished by all societies and individuals is both pursued as an end in itself or as a means to achieving other ends. As an end in itself, such transformation is an ideal or utopian state since no individual or nation could reasonably claim to be self-sufficient or needs no further development and consequently rest on her oars.

Plato will argue that all nations are at best developing; no nation could claim to have attained the zenith of development, because that state of perfection is ephemeral in the physical world of appearances but exists only in the super sensible world of forms. Corroborating the position of Plato, Lasana Keita maintained that, the word "developed', 'suggests a completed or finished process, while underdeveloped tends to imply statis or lack of progress. Keita further argued that, the technological and economic structures of European society fifty years ago have undergone palpable changes and continue to do so... European societies are in the process of development just as other societies deemed "underveloped" or "developing" $(2011 ; 116)$. In other words, the classifications of nations as "underdeveloped", "developing" or "developed" are comparison semantics. Flowing from this, it is erroneous to conceive underdevelopment as the absence of development rather, it is the low level of development of a nation state in comparison to other states at a given time. In the words of Walter Rodney, "underdevelopment is not absence of development..., rather, it makes sense only as a means of comparing levels of development." (2009: 15).

Given the obvious that static society do not exist, it follows then that human societies undergo developmental 
processes at different propensities thus, putting paid to the descriptions of the levels of transformation attained by any society at any given time as either, developing or developed. Whatever the description, humans are the pivot on which development paradigm oscillates with a view to enhancing their well-being.

Development analysis involves "what was" and "what is". It also considers what are in place in a given society in comparison with another society. In the context of this paper therefore, the concepts developed and developing are the parameters adopted in the description of how the different human societies fare in the enhancement of human wellbeing particularly within their locality in the areas of economy, infrastructures, science and technology or, as aptly put by Amartya Sen, the concept could describe the level of freedom, growth in gross national product, rise in personal incomes, industrialization, technological advancement, or social modernization. $(2000 ; 3)$. In other words, development is a word of pluralistic dimensions hence technological development, scientific development, political development, cultural development, educational development etcetera but central to these different dimensions is the enhancement of human wellbeing.

More importantly, and without prejudice to the explanations already made concerning developing and developed, Africa is categorised as either underdeveloped or developing. The poser has been why has development eluded the continent? Why is it that previous solutions to ensure sustainable development in the continent have yielded marginal benefits? Are there ways by which all the factors responsible for the underdevelopment of Africa can be holistically addressed and sustainable development guaranteed?

\section{The Externalist and Internalist Debate}

Diverse opinions exist on the causes of Africa's underdevelopment, the opinions could be broadly categorized into two schools of thought; the externalists and internalists. Both schools of thought are in agreement that the reality that stares the human face in contemporary Africa is that of underdevelopment. At the same time, some members of the externalist camp also shares the sentiments of the internalist camp. The externalists, such as Walter Rodney (2009), Ali Mazrui (1980), Frantz Fanon (1968), Ogundowole Kolawole (2014), Muyiwa Falaye, Femi Mimiko $(1999 ; 26)$ argued that external factors that included slave trade, colonialism and capitalism are responsible for Africa's state of underdevelopment. These foreign activities particularly colonialism, "split peoples of same stock, merged together disparate groups who historically did not get along and may never get along" (Ogundowole Kolawole 2014; 12 ), deprived Africa of her earlier brands of productive and skilled class, truncated and stunted the steady growth of traditional development, and made the continent vulnerable for domination. In the words of Ali Mazrui, "The West harmed Africa's indigenous technological development in a number of ways" (164). The collapsed infrastructure is due to the "shallowness of Western institutions," "the lopsided nature of colonial acculturation" and "the moral contradictions of Western political tutelage" (202) (cf Ayittey, George B. N. 2005). In the same vein, Femi Mimiko argued that, "slave trade and colonialism combined to re-order and change the hitherto prevailing situation and distorted Africa's steady march to progress. Slavery marked the first act of penetration of the African subsystem which subsequently ensured the incorporation of the continent into the expanding world capitalist economy as a satellite, while colonialism marked the most important phase in the incorporation of all colonial people into the global economic system as dominated and controlled by the industrial capitalist states of the West" (1999: 269)

As remedy to the contretemps Muyiwa Falaiye, and Femi Mimiko argued for reparation, debt cancellation and the restructuring of the global economic order while Ogundowole argued for re-definition and re-ordering of African communities $(2014: 117)$ with a view to engendering a reversal to the precolonial, traditional, natural, historically evolved states, empires and kingdoms with natural boundaries, historical, lingual etc demarcations, (2014:11) as some of the practical steps for global justice and development

The internalists on the other hand did not deny the negative roles of the external factors but argued that more fundamental is how Africans underdeveloped Africa. The internalists argument is anchored on the reality that most African countries gained independence several decades ago, (for instance, Ghana 1957, DRC 1960, Nigeria 1960, Uganda 1962, Somalia 1960, Sudan 1956), thus they have enough time to put behind them the colonial hiccups. More so, when the continent is blessed with abundant human and natural resources. According to Ali Mazrui, "it is fair to say the continent has $96 \%$ of non-communist world's diamonds, $60 \%$ of its gold, $42 \%$ of its cobalt, $34 \%$ of its bauxite and $28 \%$ of its uranium. Africa's iron reserves are probably twice those of the United States, and its reserves of chrome are the most important by far outside the Soviet Union" ( 1980:71) but woefully failed to overcome whatever stumbling blocks to development. Evidence abounds of countries that were exposed to the triadic factors of slave trade, colonialism and capitalism but have surmounted the challenges of underdevelopment. Consequently, "misguided leadership, misgovernance, systemic corruption, capital flight, economic mismanagement, declining investment, collapsed infrastructure, decayed institutions, senseless civil 
wars, political tyranny, flagrant violations of human rights, and military vandalism.”.(Ayittey, George B. N 2005) were identified as the clogs in the wheel of Africa's developmental quest.

Leadership involves, among other things good management of human and judicious application of natural resources for the promotion of general good. It is obvious that African countries suffered dearth of visionary, moral and ethical leaders. These negative traits that defined leadership in Africa informed the submission of Chinua Achebe, that "the trouble with Nigeria is leadership". One can say if leadership default is Nigeria's problem then something was wrong with the processes leading to their emergence. Most of the leaders that have emerged in Africa, especially Nigeria are accidental and ill prepared for governance. The processes that produced these leaders are manipulated as attested to by violent-conflicts that characterised post elections periods in most African countries. Again, most of the leaders fraudulently cling obstinately to power in spite of poor performance. Leadership and corruption in Africa, and by extension in Nigeria appears to be Siamese twin. Most African leaders are richer than the countries that produced them, while developmental drives are left basking in the wilderness. In the same vein, the followers did not fare better as many of them aids and abets the shortcomings of the leaders through frivolous demands and failure to openly check the excesses of the leaders. While the leaders display insincerity to issue of development, the followers appeared to lack maintenance culture on the few developmental efforts made, hence shoddy, abandoned or white elephants projects littered the nooks and crannies of towns and villages. This dearth of morals among leaders and followers undermined development in Africa. In other words, African leaders and followers have not imbibe moral virtues required for achieving genuine and sustainable social development. Suffice it to say that traditional African political system had set of moral codes that ensure trust and shared values required for proper functioning of contemporary African society. It is this moral aspect that constitutes the hallmark of the qualitative dimension of social development. I will return to this shortly.

\section{Analysis of Social Development in Africa}

In simple term, Social development is the appropriation for maximal societal benefits of all the economic, intellectual, technological, human, and natural resources available in a given society. For the sake of analysis, four conceptions of development are discernable these include; the western paradigm, growth related perspective, the dependence view point and lastly, human dignity stand point

When the development of a society is predicated on the extent to which such society is able to adopt and apply western political values such as democracy or socio- values that relate to consumption patterns and the maintenance of western standards of living reference is to the western paradigm. Colonialism, capitalism and globalization have helped tremendously in advancing the course of the western paradigm.

In the second conception of social development, that is, the growth related perspective emphasis is placed on wealth creation by a given society which does not necessarily translate to improved quality of life of members of the society. In other words, the higher the Gross National Product of a society the greater it's possible ranking as developed and vice versa in the growth centred conception. Furthermore, social development is often conceived in the light of the relationship of dependence that exists between two societies. In this wise, most countries of Africa, Latin America and Asia depend heavily on western industrialised countries for survival hence, they are seen as undeveloped. Finally is the conception of development that is essentially anchored on the promotion and protection of human dignity. In this regard, the main consideration of this conception of development is how the totality of human efforts impacted positively on the lives of the people through the mitigation of unemployment, scaling down the level of poverty and the bridging the inequality gap. In essence, social development in this regard involves the combination of the first three conceptions highlighted if and only if, they translate into improvement in the standard of living and overall general welfare of the generality of members of society. (L.Harrison and S Hunttington 2000: 20-21). It is thus cognitively appropriate to understand social development as the maximization of the benefits accruable to a society from its technological advancement, improvement in Gross National Product, less reliance on other societies, minimal level of unemployment and poverty rates. In other words, social development entails both tangible and intangible, physical and mental, material and immaterial objects. Aptly put, social development is both quantitative and qualitative in addressing adequately human wellbeing.

\section{The Qualitative and Quantitative Aspects of Social Development}

Monism and Dualism represents two opposing schools in the interpretation of reality. The issues of development also exhibit similar but not perfectly equivalent view. While monism on the one hand, emphasised a single approach to the comprehension of reality which could be in the form of ideas or material, hence monist idealism or monist materialism. Development could as well be construe from the perspective of the material or mental, 
but not both in the case of Africa. In this regard, the material components of development does not take cognizance of the mental or spiritual and consequently is in quantitative returns. In the same vein, the mental components of development construe development only in terms of the intangibles and no more. Dualism on the other hand argued for the mental as well as the material to be the constituent elements of reality. The dualistic approach to development in the view of this author, placed the mental, the qualitative, as well as the physical, the quantitative on the same pedestal for meaningful development. In other words, the qualitative and the quantitative returns defined sustainable development.

In Africa, the quest for development is approached from a single rather than dualistic perspective. Emphasis is on the establishment of industries, provision of energy, constructions of buildings, roads and other tangible infrastructure which mainly represents the quantitative dimension of development. The qualitative aspect of development is adequately exemplified by the socio-ethical values of the society. This socio-ethical dimension of development in human society emphasizes the positive contents of culture, norms and values of the people in any transformation. Values and sustainable development are two sides of a coin: social development devoid of societal values, particularly cultural values can never be sustainable. Values are not only guides to human thoughts and feelings but are the fulcrum that underlie human actions. For sustainability to be ensure, social development must countenance "the humanistic and spiritual aspect that emphasizes humanness, integrity, justice, freedom of the individual, harmony, community, self-fulfilment and contentment" (J. N. Kudadjie 1992: 208), such development must place the human person, its aspiration and dignity at the centre of any transformation. It is this "positive changes in social structures, attitudes and institutions in ways that would facilitate an improved standard of living" (Ekanola Adebola B and Lawal Ademola L 2016: 62) that mainly define meaningful and genuine social development. Accordingly,

As a society, our goals should be looking at development

that sustains values reflecting progress in our relationships

with one another as human beings, our place in the natural

environment, and consequently developments in what it

means to be human. (Stead and Stead, 2000)

This is more so when socio ethical values that facilitate harmonious relations will preserve the African race, check abuse of scientific and technological innovations and redirect its ideas towards the enhancement of human wellbeing rather than serving as tools of human destruction. Aptly put, socio ethical values will engender the treatment of human beings with dignity.

In the case of Africa, the build-up to socio ethical dimension of development includes the transition from tradition to modernity orchestrated by the contacts of Africans with other cultures through trans-Atlantic trade, colonialism and more recently globalization. However, such transition neglected some positive traditional African communal moral values and social structures such as, care, humility, fraternity and mutuality that provides the basis for social harmony as it romances hook, line and sinker with western value system. (Ikuenobe Polycarp 2016:56)

The educational system that would have had as one of its focuses the re-enactment of these positive socio-ethical values in Africa, so as to have what Godwin Sogolo (1994: 132) appropriately referred to "as continuity in change" is under threat due to the emphasis placed on the disciplines of Science, Technology, Engineering and Mathematics (STEM) or science and technological development. In other words, successive governments in Africa strive to stem the tide of underdevelopment through emphasis on the disciplines of science and technology in their educational policies as way of accelerating development (O.A.Balogun 2006:401-402, Makinde, M.A. 2014:567 ),This is being done through the establishment of specialised tertiary institutions, improved funding and grants for research in the areas of STEM. Admission policies that favours STEM over humanities etcetera. All these suggest the priority placed on the quantitative aspect of social development over the qualitative.

\section{The Ethics of Complementarities.}

Ethics could be define as the "science of human behaviour whose subject matter is the discovery of the appropriate manner of conducting human affairs" (Omazu 2012:10). The most appropriate manner by which sustainable social development can be achieved in Africa involves a synthesis of what has already been described in the dualistic conception of social development as the qualitative and quantitative aspects of development. The inherent values derivable from this synthesis is what the author refers to as ethics of complementarities. 
In the qualitative aspect, morality and cultural values of the society play important roles, they are the fulcrum of what constitute the necessary and sufficient conditions required for achieving developments in this sense. In achieving this, the negative attitudes of Africans towards government properties must pave way for maintenance and sustenance culture. There must be a shared moral vision for public goods and services, unlike the pervasive impressions in Nigeria that public property is no one property and could be treated with disdain. In addition, is the dire need to cultivate the spirit of what Olatunji Oyeshile refers to as "the democracy of development"(2016: xix) so as to stem the tide of people-government divergence. Democracy of development is anchored on reasoned reconciliation of disagreement occasioned by leaders| and followers on positive development. It is on record that leaders with good and sincere developmental intentions for a society may be opposed by members of the potential benefitting society as in the reported cases of a Nigerian government well-articulated proposal to dredge the River Niger so that its waterways would be open to big ships and consequently impacts on the economic and social development but, which was opposed by the communities through which the River Niger passed (2016: xix) or the opposition to the release of fund from the excess crude account to fund the procurement of arms to fight insurgency in some parts of the country.

Furthermore, Africa must be cautious and reflective on the adoption hook, line and sinker of what constitutes morality in other cultures. This is necessary because culture and values cannot be divorce from sustainable development: an adopted culture and values must not be at variance with the indigenous ones if social development is to be guaranteed. The culture of the west sustains developmental drives in the west that may not necessarily be so in Africa. Social development in Africa need not be patterned along European line. Every society has its history, events and experiences that are needed to formulate policies for the future more so, when what defines morality in Africa differs from that of Europe and America. Suffice it to say that, scholars particularly, Julius Nyerere (1971), Godwin Sogolo, Toyin Falola $(2016: 14)$ have argued for a recourse to the moral and cultural values that sharpened organic communities in precolonial Africa as a veritable guide against corruption, greed, vandalism, lack of maintenance culture and other social vices that defines contemporary Africa. The upshot is that Africans could and should create a niche for herself in achieving the qualitative dimension of the dual aspects of social development.

A perspective of social development would rank societies that have recorded appreciable progress in the field of science and technology or trade and investment but morally deficient as developed. This is the development that most African nations have pursued relentlessly since independence. In this regard, the quest for development is patterned along the lines of Europe and America. True and genuine social development desirable by Africans would be evident in the availability of basic necessities of life which undeniably, science and technology has continually provided as well as, the demonstration of mental dispositions for caring commitments to actualizing the advancement of contemporary and future aspirations of the people, by determining the values and identifying the needs of society, which is in the purview morality.

In the quantitative dimension therefore, all the other spheres of development, including scientific and technological development can be synthesize for the enhancement of human wellbeing in Africa. What Africa needs is socio-technological development and not merely technological development where energies and resources are presently deployed. Socio-technological development gives cognizance to the moral values of the society even as it cherishes the material or tangible aspect of development.

In other words, social development could be likened to a two-sided coin: both sides of the coin are of equal relevance, the defacement of any of the sides renders void the validity of the coin as a legal tender. The qualitative and the quantitative are indispensable partners for enduring social development. Emphasis on one at the expense of the other is to "...risk becoming a society that loses its balance, rather like an athlete who builds just one side of his body on the false assumption that he only needs strength in the limbs and muscles that actually passed the football or haul the javelin" (Isaac E. Ukpokolo $2015: 22$ )

The qualitative as well as quantitative aspects of development are of equal importance to Africans social existence. The quantitative aspect is epitomised essentially by science and technology as demonstrated by the "establishment of industries, construction of buildings and roads, and laying a whole host of infrastructure" (J.N.Kudadjie 1992: 207). The qualitative aspects involve the humanistic and spiritual components that include humanness, ethics of care and maintenance of commonwealth, integrity, justice, equality and freedom.

Unfortunately, the disciplines of humanities, which are charged with the responsibilities of entrenching in the people the positive character traits required of the qualitative dimension of social development are threatened by the preference of the disciplines of science, through special concessions granted on funding, admission quota and other supports for students and researchers in science technology by governments in Africa. Much has been 
written by scholars to agitate for equilibrium point so as to facilitate peaceful and enduring social order in society hence, energy would not be dissipated in this direction. Suffice it to say, the pursuit of technological advancement without a concomitant emphasis on the ethics of the people is dangerous to human existence.

\section{Conclusion}

The paper observed that the quest for transformation from less desirable condition of existence to a more desirable condition capable of enhancing meaningful life has occupied the centre stage of discourse among individuals and nations. It was noted by the externalists and internalists that the attainment of a commendable stage of development has been a mirage to the continent of Africa in spite of the fact that, " nature or providence has treated the continent as the most beloved in the world" having being blessed with abundant human and natural resources (Segun Ogungbemi 2007 :28), due to slavery and colonialism which bastardized indigenous socio-political and economic structures of the continent. Also identified is the dearth of leadership and the attendant people-government divergence. To stem the tide of underdevelopment in Africa, successive governments embarked on a paradigm shift that favours science and technology at the detriment of the humanities in the quest for development.

Although, advancement in science and technology has become the parameter for the classification of nations as developed, developing or underdeveloped. However, this advancement is akin to the Trojan 'horse with positive and negative dimensions. On the positive side, technology improves agricultural production, medical advancements including reduction in mortality rate, transportation and communication (Makinde Moses 2007: 452- 453). On the negative side, it facilitates violence and threatened world peace through the manufacturing and deployment of weapons of mass destruction, it encourages the intrusion on privacy, serves as instruments of domination and subjugation of weaker nations by the relatively stronger ones consequently, the innovations raise social and ethical problems that impinged on its development agenda for human wellbeing. Notwithstanding, African nations are desirous of the advancement in science and technology hence, the institutionalization of educational policies that promote the disciplines under the rubric of science and technology at the detriment of the disciplines within the purview of humanities. This paper argued that such lopsided paradigm shift would be inimical to, rather than enhance, Africa's social development. In the same vein, Social development, properly construed ought to be a synthesis of the tangibles and intangibles, the premium on the tangibles with less emphasis on the intangibles that include spirituality and morality in the case of Africa cannot ensure development as well as sustain it.

The paper argued that social development in Africa would be better appreciated for meaningful social existence when it is a dualistic conception that involves the quantitative (physical) and the qualitative (mental). In terms of the quantitative returns, efforts could be directed at replicating the achievements of science and technology by focusing on skill acquisitions, practical knowledge and technology transfer which will impact on the physical development. This, however must be moderated upon by the qualitative returns, which emphasizes the non-physical particularly, the moral. In essence, the qualitative and the quantitative aspects should be complements in the quest for social development in Africa.

\section{References}

Ayittey, G. B. N. (2005). The “Colonialism-Imperialism” Paradigm Is Kaput. Retrieved March 4, 2018, from https://www.laits.utexas.edu/africa/ads/815.html

Balogun, O. A. (2006). Humanities, Man and Technology in Africa. In D. Fashina, \& D. Ogungbila (Eds.), The Humanities, Nationalism and Democracy in Africa: A Philosophical Appraisal. Sola Akinrinade, Ile-Ife, Nigeria: Obafemi Awolowo University Press.

Ekanola, A. B., \& Lawal, A. L. (2016). Godwin Sogolo and The Metaphysics of Development. In O. A. Oyeshile, \& F. Offor (Eds.), Ethics, Governance and Social Order in Africa: Essays in Honour of Godwin S Sogolo. Ibadan, Nigeria: Zenith Book House.

Fanon, F. (1968). The Wretched of the Earth. New York: USA, Grove Press.

Harrison, L. E., \& Hunttington, S. P. (Eds.). (2000). Culture Matters: How Culture Shapes Human Progress. New York, USA: Basic Books.

Ikuenobe Polycarp. (2016). Tradition, Modernity and Social Development. In O. Oyeshile, \& F. Offor (Eds.), Ethics, Governance, and Social Order in Africa: Essays in Honour of Godwin Sogolo. Ibadan, Nigeria: Zenith Book House.

Keita, L. (2011). Philosophy and Development: On the Problematic African Development _ A Diachronic 
Analysis. In L. Keita (Ed.), Philosophy and African Development: Theory and Practice Dakar. Senegal: CODESTRIA.

Kudadjie, J. N. (1992). Towards Moral and Social Development in Africa: Insights from Dangame Traditional Moral Experience. In K. Wiredu, \& K. Gyekye (Eds.), Person and Community: Ghanian Philosophical Studies (Vol. 1). Washington, USA: The Council for Research in Values and Philosophy.

Makinde, M. A. (2007). African Philosophy: The Demise of A Controversy. Ile-Ife, Nigeria. Obafemi Awolowo University Press.

Makinde, M. A. (2014). Logico-Philosophical Studies. Ile-Ife. Nigeria: Obafemi Awolowo University Press.

Mazrui, A. (1980). The African Condition. London, United Kindom: Heneineman.

Mimiko, N. O. (1999). The Reparation Question in the Contemporary International Economic System: Bases, Strategies and Constraints. In M. Falaiye (Ed.), Africa's Political Stability: Ideas, Values and Questions. Lagos, Nigeria : Panaf Publishing Inc.

Nyerere, J. (1971). Ujaama : Essays in Socialism. London, United Kingdom: Oxford University Press.

Ogundowole, K. (2014). From Kakistocracy to Institution of Democracy. Lagos, Nigeria: Gourmet Honey.

Ogungbemi, S. (2007). Philosophy and Development. Ibadan, Nigeria: Hope.

Omazu, E. (2012). Applied Ethics (Course book for CTH 432). Lagos, Nigeria: National Open University of Nigeria.

Oyeshile Olatunji. (2016). "Foreword" Ethics, Governance, and Social Order in Africa: Essays in Honour of Godwin Sogolo. In O. Oyeshile, \& F. Offor (Eds.). Ibadan, Nigeria: Zenith Book House.

Rodney, W. (2009). How Europe Underdeveloped Africa. With an introduction by Harding, V. Lagos, Nigeria: Panaf Publishing.

Sen Amartya. (2000). Development as Freedom. New York, USA: Alfred A Knopf.

Sogolo, G. (1994). Continuity in Change: Alternatives Scenarios for the Future of African Culture. The Futures of Cultures. Paris, France; UNESCO Publishing.

Stead, J. H., \& Stead, E. (2000). Eco-Enterprise Strategy:Standing for Sustainability. Joumal of Business Ethics, 24(4), 313-329. https://doi.org/10.1023/A:1006188725928

Toyin Falola. (2016). The Humanities in Africa : Knowledge Production, Universities, and the Transformation of Society. Austin, USA: Pan African University Press.

Ukpokolo, I. (2015). Methodology of Research and Writings in Philosophy. Ibadan, Nigeria: Kairos.

\section{Copyrights}

Copyright for this article is retained by the author(s), with first publication rights granted to the journal.

This is an open-access article distributed under the terms and conditions of the Creative Commons Attribution license (http://creativecommons.org/licenses/by/4.0/). 